To the memory of Dr. Stanistaw Żotnierowicz who passed away so suddenly, but his impact on protein phosphatase $2 A$ understanding and our research remains Review

\title{
Protein phosphatase 2A: Variety of forms and diversity of functions
}

\author{
Katarzyna Lechward ${ }^{1}$, Olubunmi S. Awotunde ${ }^{2}$, Wojciech Swiątek ${ }^{1}$ and \\ Grażyna Muszyńska ${ }^{2}$ 凶
}

${ }^{1}$ Cell and Molecular Signaling Laboratory, Intercollegiate Faculty of Biotechnology Medical

University of Gdańsk, Gdańsk, Poland, ${ }^{2}$ Institute of Biochemistry and Biophysics, Polish Academy of Sciences, A. Pawińskiego 5a, 02-106 Warszawa, Poland

Received: 24 October, 2001; accepted: 4 December, 2001

Key words: reversible phosphorylation, protein phosphatase 2A, protein-protein interactions, signal transduction, cell cycle, carcinogenesis.

Protein phosphatase 2A (PP2A) comprises a diverse family of phosphoserine- and phosphothreonine-specific phosphatases present in all eukaryotic cells. All forms of

\footnotetext{
This work was partially supported by grants from the State Committee for Scientific Research (KBN, Poland, grant No. 6P04A06015 to S. Żołnierowicz and K.L.) and the European Community (INCO-Copernicus, IC 15-CT96-0901 to G.M.).

${ }^{\bowtie}$ Corresponding author: Grażyna Muszyńska, e-mail: muszynsk@ibb.waw.pl

Abbreviations: PP2A, protein phosphatase 2A; PP2Ac, catalytic subunit of PP2A; PR65/A, structural subunit of PP2A; PR55/B, PR/56/61/B', PR48/59/72/130/B" , and PR93/PR110/B" ", four families of PP2A variable regulatory subunits; $\mathrm{PP}_{\mathrm{D}}$ and $\mathrm{PP}_{\mathrm{T}}$, dimeric and trimeric forms of $\mathrm{PP} 2 \mathrm{~A}$, respectively; ERK/MAP kinase, extracellular receptor-activated kinase/mitogen activated protein kinase; MEK, MAP kinase (kinase activates ERK/MAP kinases); Raf-MEKK, MEK kinase; Ras-small GTPase, activated upon binding of GTP (activates Raf kinase); p70 S6 kinase, mitogen-stimulated p70 kinase of S6 ribosomal protein; GSK-3 $\beta$, glycogen synthase kinase $3 \beta$; E4orf4, adenovirus E4 open reading frame 4 product; SV 40, simian virus 40; APC, adenomatous polyposis coli; TOR, mammalian target of rapamycin; FRAP, rapamycine associated protein; PHAPI, putative class II human histocompatibility leukocyte-associated protein I; PKN, nuclear protein kinase; CG-NAP, Centrosome-and-Golgi-localized protein kinase-associated protein; HOX11, homeobox gene 11 product; HSF, heat shock transcription factor; eRF, eukaryotic release factor (the translation termination factor); $\mathrm{I}_{1}{ }^{\mathrm{PP} 2 \mathrm{~A}}, \mathrm{I}_{2}{ }^{\mathrm{PP} 2 \mathrm{~A}}$, heat stable inhibitors (1 and 2) of PP2A; SET, leukemia-associated protein; HRX, protein associated with SET.
} 
PP2A contain a catalytic subunit (PP2Ac) which forms a stable complex with the structural subunit PR65/A. The heterodimer PP2Ac-PR65/A associates with regulatory proteins, termed variable subunits, in order to form trimeric holoenzymes attributed with distinct substrate specificity and targeted to different subcellular compartments. PP2Ac activity can be modulated by reversible phosphorylation on $\mathrm{Tyr}^{307}$ and methylation on C-terminal Leu ${ }^{309}$. Studies on PP2A have shown that this enzyme may be implicated in the regulation of metabolism, transcription, RNA splicing, translation, differentiation, cell cycle, oncogenic transformation and signal transduction.

Reversible protein phosphorylation has become widely recognized as the most important reaction for the regulation of protein functioning in eukaryotic cells, being involved in switching cellular activities from one state to another and, in this way, regulating gene expression, cellular proliferation, and cell differentiation. It is the major mechanism by which cells respond to extracellular signals such as hormones and growth factors, and control all events at various stages of the cell cycle, as well as the response of the cell to environmental and nutritional stresses [1]. The intracellular phosphorylation level of proteins catalyzed by protein kinases is also regulated via dephosphorylation by protein phosphatases [2].

Coordinated control of kinases and phosphatases activities provides the cell with a capacity to rapidly switch proteins from the phosphorylated to the dephosphorylated state to meet differing physiological demands. This is perhaps best illustrated during the eukaryotic cell division cycle where decisions to proceed through different stages are made by the timely phosphorylation and dephosphorylation of specific cell cycle regulators. Thus, phosphorylation-dephosphorylation events act as switches or checkpoints ensuring that cell has fulfilled all the requirements needed to proceed to the next cell cycle stage. Errors in checkpoint control form the most prevalent basis for aberrant cell growth and can cause serious developmental consequences for an organism [3]. Therefore, there is an ongoing interest in identifying and characterizing protein kinases and protein phosphatases that modulate the phosphorylation status of proteins. Both groups of enzymes have a significant degree of complexity in structure and are subject to tight regulation. While earlier studies focused on protein kinases, it is now apparent that protein phosphatases play an equally important role in the control of the cellular level of phosphoproteins, but the knowledge about this group of enzymes is relatively limited [4]. From an evolutionary point of view, all protein kinases seem to descend from one primordial gene, whereas protein phosphatases originated from two ancestor genes, one serving as the prototype for the phosphotyrosine phosphatases family (the PTP family), the other for phosphoserine/phosphothreonine phosphatases (the PPP and PPM family) [5, 6]. Apart from distinct substrate specificity those two groups of phosphatases differ in amino-acid sequence, three dimensional structure, the mechanisms of catalysis, and in sensitivity towards a variety of naturally occurring and synthetic inhibitors [5-7]. The PPP family groups the PP1, PP2A, PP2B, PP4, PP5, PP6 and PP7 enzymes, whereas PP2C and bacterial enzymes like SpoII or PrpC belong to the PPM family [6].

\section{MULTIMERIC STRUCTURE OF PP2A}

Protein phosphatase type 2A (PP2A) is a major serine-threonine protein phosphatase in all eukaryotic cells [4-8]. PP2A can exist in vivo in a dimeric $\left(\mathrm{PP} 2 \mathrm{~A}_{\mathrm{D}}\right)$ or a trimeric $\left(\mathrm{PP} 2 \mathrm{~A}_{\mathrm{T}}\right)$ form [9-12]. $\mathrm{PP} 2 \mathrm{~A}_{\mathrm{D}}$ is composed of a $36-\mathrm{kDa}$ catalytic subunit $\left(\mathrm{PP} 2 \mathrm{~A}_{\mathrm{C}}\right)$ tightly bound to the $65 \mathrm{kDa}$ regulatory (PR65/A) constant subunit. These two associated proteins form the core dimer which is able to further interact with a third, variable subunit or other regulatory proteins, as illustrated in Fig. 1. The PP2A catalytic subunit, present in the 


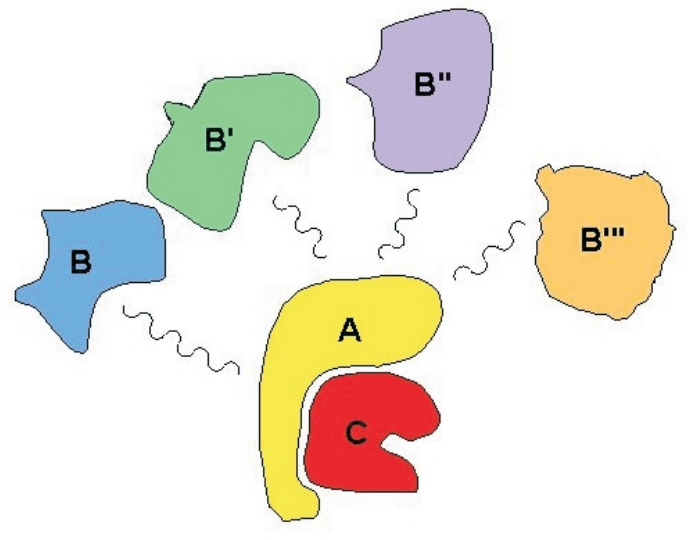

Figure 1. Schematic strucuture of protein phosphatase 2A (PP2A) holoenzymes.

$\mathrm{C}: \mathrm{PP} 2 \mathrm{Ac} \alpha, \beta$-catalytic subunits; A: PR65/A $\alpha, \beta$-constant regulatory (structural) subunits; $\mathrm{B}: \mathrm{PR} 55 / \mathrm{B} \alpha, \beta$, $\gamma, \delta ; \mathrm{B}^{\prime}: \mathrm{PR} 56 / 61 \alpha, \beta, \gamma, \delta, \varepsilon ; \mathrm{B}^{\prime \prime}: \mathrm{PR} 48 / 59 / 72 / 130$; $\mathrm{B}^{\prime \prime \prime}$ : PR99/110-variable regulatory subunits. Greek letters refer to distinct genes encoding subunits of PP2A.

$\alpha$ and $\beta$ isoforms, is encoded by two genes, whose products share $97 \%$ identity [13]. Molecular cloning of PP2Ac has revealed that PP2Ac is one of the evolutionarily most conserved proteins. The identity between the human and budding yeast amino-acid sequence of PP2Ac is $86 \%$ (for a review see [14]).

The second component of PP2A core dimer is PR65/A, which also exists in two ( $\alpha$ and $\beta$ ) isoforms. PR65/A is composed of 15 tandemly linked leucine rich repeats (HEAT motifs) containing from 39 to 41 amino-acid residues [14]. HEAT motifs can be found in a variety of proteins including huntingtin, elongation factor 2 or the lipid kinase TOR. These motifs are implicated in mediating protein-protein interactions. A single HEAT motif is composed of a pair of antiparalel $\alpha$ helices connected with a short, 1-3 amino-acid intrarepeat loop. In the PR65/A molecule the HEAT repeats are stacked almost parallel to each other, creating an elongated, left handed structure resembling a hook. Interrepeats loops serve as sole joining elements whereas the intrarepeats loops provide a highly hydrophobic surface for protein-protein contacts between PR65/A and both the catalytic and the variable subunits. Therefore the PR65/A subunit serves as a scaffolding molecule to coordinate the assembly of the PP2A holoenzymes, generating functionally diverse heterotrimers [14].

The variable $B$ subunits are classified into four families of unrelated proteins: the PR55/ B family with four isoforms $(\alpha, \beta, \gamma, \delta)$; the PR56/61/B' family encoded by five genes $(\alpha$, $\beta, \gamma, \delta, \varepsilon$ ), some transcripts of which undergo alternative splicing to generate up to eleven isoforms, and the PR48/59/72/130/B" family containing four proteins generated by alternative splicing of a single gene, as well as the product of a closely related gene [7-9, 11]. The fourth family, PR93/PR110/B"', discovered recently by Moreno et al. [15], comprises of two unrelated proteins encoded by two different genes. Many B subunits are expressed during specific developmental stages and show a tissue specific expression, which creates an additional level of PP2A regulation. The variable regulatory subunits control the activity and specificity of the holoenzyme and target it to different cellular compartments $[6,16]$.

To date, in mammalian cells cDNAs have been identified for two PR65/A subunits, two PR65/C subunits, and over twenty B subunits $[8,10]$. This suggests the existence of numerous PP2A complexes. The many known PR/B regulatory subunits - including splice variants - theoretically could form more than 50 different trimeric holoenzymes [8].

\section{FUNCTIONS OF THE VARIABLE REGULATORY SUBUNITS}

Members of four unrelated protein families called $\mathrm{PR} / \mathrm{B}, \mathrm{PR} / \mathrm{B}^{\prime}, \mathrm{PR} / \mathrm{B}^{\prime \prime}$, and $\mathrm{PR} / \mathrm{B}^{\prime \prime}$ ' have been identified in different holoenzyme complexes (Fig. 1). It has been speculated that each PP2A holoenzyme serves a distinct function.

\section{PR55/B subunits}

Using different approaches, including mutational and deletion analysis, the func- 
tions of PR55/B complexed to the core dimer of PP2A were elucidated [12]. A strain of Saccharomyces cerevisiae lacking the CDC55 gene, corresponding to human PR55/B gene, was defective in cytokinesis, producing long unbudding cells, unable to grow at low temperatures [17]. Drosophila melanogaster mutants carrying a transposon inactivated $\mathrm{PR} 55 \alpha / \mathrm{B} \alpha$ gene showed abnormal anaphase resolution of chromosomes. The anaphase defect, lagging chromatids, points to a more direct role of the PR55/B subunit in the segregation of chromatides [18]. In mammalian cells, conditional knock-out of the PR55 $\alpha / \mathrm{B} \alpha$ subunit influenced cell shape, showing that the association of PP2A via vimentin with the cytoskeleton is $\mathrm{PR} 55 \alpha / \mathrm{B} \alpha$ dependent [19]. The $\mathrm{PR} 55 \beta / \mathrm{B} \beta$ subunit was found to be a neuronal specific isoform, but there is no direct evidence linking the $\mathrm{PR} 55 \beta / \mathrm{B} \beta$ containing holoenzyme to any function in the nervous system [20].

\section{PR56/61/B' subunits}

The regulatory subunits of the PR56/61/B' family have different subcellular localization and tissue specificity [21]. Many of PR56/61/ B's can be reversibly phosphorylated, which can promote their association with the core dimer and subsequently modulates the phosphatase activity of PP2A. Moreover, the holoenzymes containing some PR56/61/B' subunits form complexes with cyclin G, a protein whose expression is regulated by the tumour suppressor p53. Cyclin G forms a complex with $\mathrm{B}^{\prime} \alpha$ only after induction of synthesis of p53 in p53 temperature-sensitive cell lines. Induction of p53 synthesis by a variety of cellular stresses [21] appears to be required for the formation of this complex [22]. Therefore, the existence of a cross talk between PP2A and p53-mediated pathways has been suggested. These results indicate that the formation of the complex between cyclin $G$ and the PR56/61/B' $\alpha$ subunit of PP2A is regulated by p53 [23]. Cells overexpressing PR56/61/B' $\alpha$ are blocked in late G1 phase of the cell cycle.
Another example of the involvement of PR56/61/B' containing PP2A holoenzyme in the regulation of cellular processes is the recruitment of this subunit to APC (adenomatous polyposis coli), a component of the Wnt signaling pathway [24].

It has been suggested that the $\mathrm{B}^{\prime}$ subunit may direct PP2A to dephosphorylate a specific component(s) of the signaling complex. The $\mathrm{B}^{\prime}$ subunit, but not $\mathrm{B} \alpha$ subunit, regulates the Wnt pathway [25]. The Wnt signaling pathway is described separately.

\section{PR48/59/72/130B" family subunits}

PR72/B" containing holoenzyme is an activator of simian virus 40 (SV40) replication, whereas PP2A containing PR55/B is inhibitory for this process [26]. Recent data suggest that PP2A can be implicated in chromosomal replication, exerting its effect via binding of $\mathrm{PR} 48 / \mathrm{B}^{\prime \prime}$ to Cdc6, a human replication initiator protein [27].

Another member of this family, PR59B' , after UV-irradiation was found to associate and dephosphorylate p107, a retinoblastoma-related cell cycle regulatory protein. Dephosphorylation of $\mathrm{p} 107$ leads to the expression of DNA damage response genes [28]. Regarding the experimental data, it may be presumed that the PR48/59/72/130/B" family may be involved in the regulation of the $\mathrm{G}_{1} / \mathrm{S}$ transition [27].

\section{PR93/PR110/B"' subunits}

Two calmodulin (CaM) binding proteins, namely striatin and $\mathrm{S} / \mathrm{G}_{2}$ nuclear autoantigen (SG2NA), form stable complexes with the dimeric form of PP2A (PP2A $\left.A_{D}\right)$. Striatin has been reported to associate with the postsynaptic densities of neurons, whereas SG2NA has been reported to be a nuclear protein expressed primarily during the $\mathrm{S}$ and G2 phases of the cell cycle. In addition to CaM and $\mathrm{PP}_{2} \mathrm{~A}_{\mathrm{D}}$, several unidentified proteins stably associate with the striatin- and SG2NA- 
complexes. These proteins could be involved in targeting and organizing PP2A with components of a $\mathrm{Ca}^{2+}$-dependent signaling pathway(s) [15].

Moreover, proteins encoded by the genomes of DNA viruses, such as the small-t antigen of simian virus (SV40) and small-t and middle T antigens of polyoma virus (PV), may also function as variable regulatory subunits [29]. The role of these antigens in complexes with PP2A is summarized in Table 1 . The available data indicate that alteration of phosphatase activity and subsequent changes in protein phosphorylation levels is crucial step in cell transformation by these viruses [30, 31]. Another viral protein, E4/orf4 of adenovirus has been found to associate with PP2A. Probably this complex is responsible for the downregulation of AP-1 transcriptional activity that occurs during viral infection [32]. A complex of two HIV-encoded proteins binds and activates the trimeric form of PP2A [33]. Millward, Zolnierowicz \& Hemmings [8] provided a possible explanation why so many viruses have chosen PP2A as their cellular target. In order to reproduce, a virus must subvert the signal transduction machinery of a host cell to promote its survival and replication. Because PP2A is an essential regulator of protein kinase cascades, it is an ideal target for the viruses [8].

\section{ROLE OF PP2A IN SIGNAL TRANSDUCTION}

PP2A is responsible for controlling stimulus activated protein kinases. Upon cell stimulation, specific kinases are transiently phosphorylated and activated. Several of these protein kinases are substrates for PP2A. This phosphatase appears to be a major kinase phosphatase in eukaryotic cells that downregulates activated protein kinases [8]. PP2A controls the activities of several major protein kinase families, in particular protein kinase B (PKB also known as Akt), protein kinase $\mathrm{C}$, p70 S6 kinase, calmodulin dependent kinases, MAP kinases and cyclin-dependent kinases (for a review see [8]). The RAS-RAFMEK-ERK/MAP kinase cascade plays a central role in mediating cell-cycle and transcriptional responses of many cell-surface receptors. This pathway is usually only transiently activated, and its constitutive activation is sufficient to cause oncogenic transformation of some cells [34]. PP2A plays a role in the downregulation of the ERK/MAP kinase pathway. PP2A can dephosphorylate and inactivate MEK1 and ERK-family kinases [35]. Expression of SV 40 small-t antigen (which inhibits PP2A) activates MEK1 and ERK, which may explain how small-t antigen promotes transformation [36, 37].

There are also data which provide a link between apoptosis and the signal transduction pathway involving PP2A and MAP kinase. Caspase-3, the most extensively studied of all caspase family members, has a role in apoptosis [38, 39]. This protease cleaves key enzymes involved in DNA repair, such as poly (ADP-ribose) polymerase and DNA-dependent protein kinase, and renders them inactive. Caspase-3 also cleaves the regulatory subunit PR65/A of protein phosphatase 2A. PR65/A was found to be a substrate for caspase-3 but not for caspase-1 (another caspase family member). The induction of apoptosis activates caspase-3, then causes up-regulation of PP2A activity. The increase in phosphatase activity is carried out by cleavage of the regulatory PR65/A subunit. Then, the activated free catalytic subunit of PP2A dephosphorylates MAP kinase.

PP2A, through interaction with Tap42/ $\alpha 4$ (the regulatory component in the rapamycinsensitive TOR signaling pathway), is also involved in the rapamycin-sensitive pathway that connects extracellular stimuli to the initiation of mRNA translation. A protein, $\alpha 4$, that associates constitutively with the catalytic subunit of PP2A, shares 37\% homology with Tap42, a $S$. cerevisiae protein that has been reported to associate with PP2Ac and Sit 
phosphatase (yeast phosphatase closely related to PP2A) [40]. The association of $\alpha 4$ with PP2A in the cell is blocked by rapamycin [41]. Therefore, PP2A may participate in the mammalian rapamycin-sensitive pathway.

Also another protein, a transcription factor encoded by a homeo box gene (Hox 11), associates with the catalytic subunit of PP2A [42]. This interaction is thought to affect cell cycle progression. PP2A has been shown to interact with the heat shock transcription factor 2 (HSF2) that mediates the stress-induced expression of heat shock protein genes (hsp). HSF2 is also required for normal cell function, even in the absence of stress and is important for cell cycle progression. HSF2, a member of HSF family, interacts with the PR65/A subunit of PP2A. The presence of the regulatory subunits in PP2A holoenzymes limits the activity of the catalytic subunit [43]. Due to the competition between HSF2 and the catalytic subunit for the same binding site on PR65/A, HSF2 binding to PR65/A blocks its interaction with the catalytic subunit. Therefore, overexpression of HSF2 stimulates the PP2A catalytic subunit activity in the cell, indicating the importance of HSF2 as an in vivo regulator of PP2A. These results identify HSF2 as a dual function protein, capable of regulating both $h s p$ expression and PP2A activity. This could function as a mechanism by which $h s p$ expression is integrated with the control of cell division or other PP2A regulated pathways [44].

The translation termination factor eRF1 (eukaryotic release factor 1) has been found in the polysomal fraction complexed with PP2A. Thus, eRF1 appears to represent a novel PP2A-targeting subunit that may serve to bring the phosphatase into contact with putative ribosomal targets among the components of the translational apparatus [45, 46]. Recently, PP2A was shown to participate in degradation of $\beta$-catenin, thus regulating Wnt- $\beta$-catenin signaling. The adenomatous polyposis coli (APC) protein, axin and glycogen synthase kinase $3 \beta$ form a Wnt-regulated signaling complex that mediates the phosphorylation-dependent degradation of $\beta$-catenin [25]. Dysregulation of Wnt- $\beta$-catenin signaling disrupts axis formation in vertebrate embryos and underlies multiple human malignancies including colon, skin and liver cancers. The Wnt-regulated signaling complex mediates the phosphorylation-dependent degradation of $\beta$-catenin, which activates transcription of genes responsible for growth and development. $\beta$-Catenin binds the signaling complex, where it is phosphorylated by glycogen synthase kinase $3 \beta$ (GSK3 $\beta$ ). This phosphorylation results in the ubiquitin-mediated proteasomal degradation of $\beta$-catenin (Fig. 2). Wnt signaling leads to inactivation of GSK3 $\beta$ which results in the accumulation of $\beta$-catenin

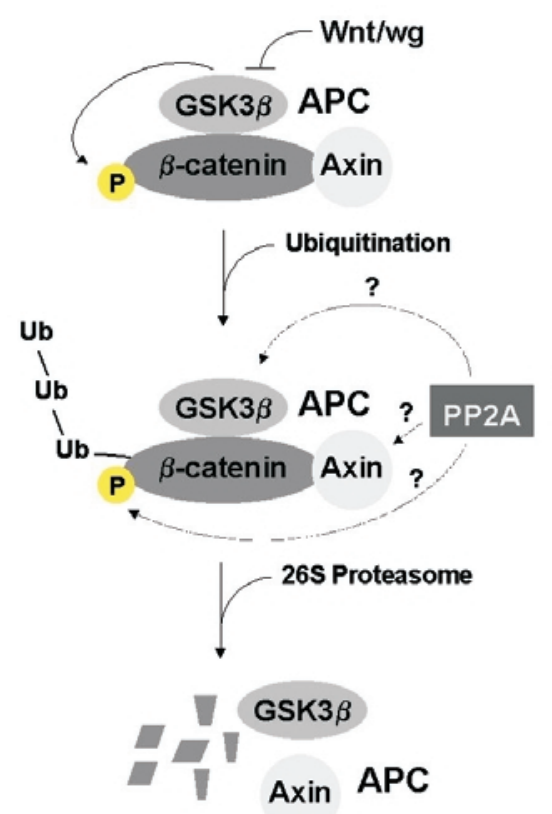

Figure 2. Postulated role of PP2A in Wnt/wg signaling.

In the absence of Wnt/wg the proteins GSK3 $\beta$, APC and axin associated and phosphorylate $\beta$-catenin. This phosphorylation targets $\beta$-catenin for ubiquitination followed by proteasome degradation. In the presence of Wnt/wg degradation of $\beta$-catenin is blocked, leading to its accumulation. $\beta$-Catenin is a coactivator for the transcription factor TCF/LEF-1 [47]. Most probably, during the Wnt/wg signalling PR56/61/B' regulatory subunit direct PP2A to dephosphorylate specific components of the APC-dependent signalling complex and thereby inhibit Wnt signalling [24, 25]. 
and activates transcription. The role of PP2A in the regulation of Wnt signaling is not completely explained, since at least three proteins appear to be controlled by reversible phosphorylation; namely, GSK3 $\beta$, axin and $\beta$-catenin. Recent evidence suggests that PP2A specifically inhibits Wnt signaling and appears to be essential for $\beta$-catenin degradation, since $\beta$-catenin degradation could be reconstituted in phosphatase-depleted Xenopus egg extracts by PP2A, but not PP1 [24]. Moreover, expression of PR56/61/B'reduces the abundance of $\beta$-catenin and inhibits transcription of $\beta$-catenin target genes [25]. It has been suggested that PR56/61/B' may direct PP2A to dephosphorylate a specific component of the APC-dependent signaling complex and play a role in development and carcinogenesis $[24,25]$.

\section{THE ROLE OF PP2A IN CARCINOGENESIS}

The disfunction of PP2A leads to severe consequences on cell metabolism and viability. Mice lacking PP2Ac $\alpha$ (created with the knock-out technology) die during early stages of embryogenesis, whereas mice lacking the $\beta$ isoform of PP2A appear to be normal. Embryonic lethality is probably a result of cell adhesion defects caused by insufficient level of proteins associated with membranes [48]. Several pieces of evidence indicate that perturbation of $\mathrm{PP} 2 \mathrm{~A}_{\mathrm{C}}$ activity are implicated in carcinogenesis. Inhibition of PP2A activity by inhibitors like okadaic acid, calyculin A, microcistins and nodularins induces many types of cancer [49]. Contrary to that, fostriecin the potential anticancer agent inhibitor of topoisomerase II which blocks proliferation of mammalian cells, inhibits PP2A activity [50]. Moreover, the mutations of the PR65 $\beta / \mathrm{A} \beta$ genes were found in such cases as lung and colon tumors, melanomas and breast cancers $[51,52]$. For example one deletion mutation generated a truncated $\mathrm{PR} 65 \beta / \mathrm{A} \beta$ protein that was unable to bind catalytic subunit of the PP2A holoenzyme.

The above data indicate that PP2A plays a role in tumor development.

\section{ROLE OF PP2A IN CELL CYCLE PROGRESSION}

Cell cycle progression is controlled by cyclin-dependent protein kinases (Cdk)-cyclin complexes. Cdks activities are regulated by reversible phosphorylation [53]. Several studies have reported a role for PP2A in the G2/M transition, in particular, in negatively regulating Cdc2 protein kinase, which forms a complex with cyclin B [54]. Cdc2 activity is dependent on Thr 161 phosphorylation, and PP2A seems to be the phosphatase involved in its dephosphorylation and inactivation. There are two other important phosphorylation sites on Cdc2: Thr 14 and Tyr 15 and their status is controlled by Wee1 kinase and cdc25 dual-specificity phosphatase. PP2A also inactivates Cdc2 indirectly by two mechanisms: activation of Wee1 kinase and inactivation of the dual-specificity phosphatase Cdc25 (Fig. 3).

\section{CELLULAR REGULATION OF PP2A ACTIVITY}

PP2A plays many different functions and therefore is subjected to multi-level tight regulation. PP2A is regulated on the levels of translation of mRNA coding for PP2Ac, posttranslational modifications of the catalytic subunit of PP2A, and protein-protein interactions. Many cellular and viral proteins are able to interact with PP2A. Apart from a number of protein kinases, substrates of the phosphatase (see above Role of PP2A in signal transduction), the PP2A interacting proteins play a role in the modulation of activity and specificity of the phosphatase and some other 


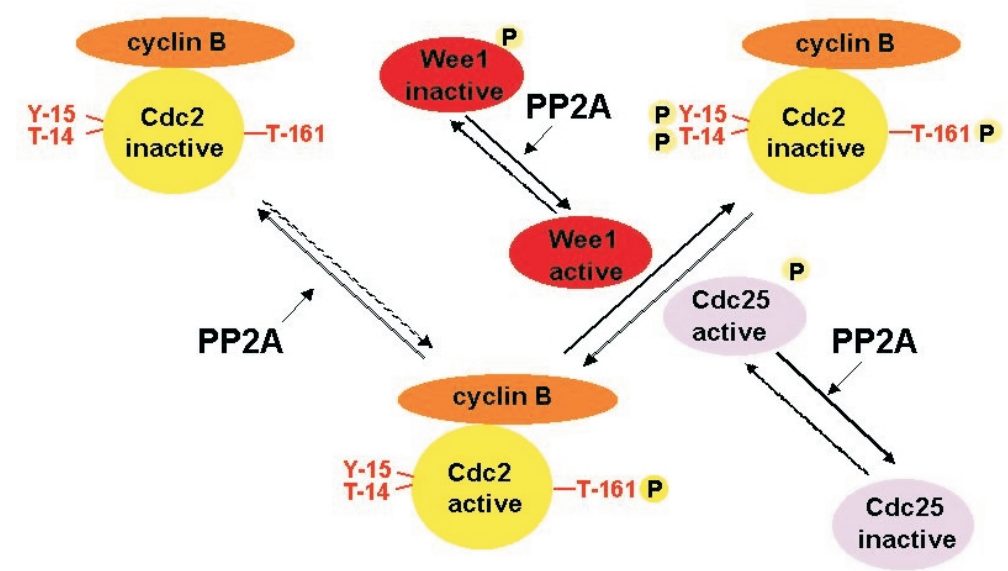

Figure 3. Possible mechanisms for regulation of Cdc2 by PP2A (according Millward et al. [8], modified).

PP2A negatively regulates progression through mitosis by direct inactivation of Cdc2 (dephosphorylation of threonine 161). The indirect effect of PP2A on Cdc2 is through the activation of the Wee1 kinase and inactivation of the Cdc25 phosphatase. Phosphorylation by the dual specificity Wee1 kinase as well as lack of dephosphorylation by the dual specificity Cdc25 phosphatase blocks Cdc2 activity.

proteins and in organization of high molecular mass complexes (Table 1 and ref. [8]).

\section{Auto-inhibitory effects on translation of PP2Ac}

PP2A is constitutively expressed in eukaryotic cells [13]. A pool of PP2A (1-2\% of total $\mathrm{PP} 2 \mathrm{~A}$ ) is associated with the polysomal fraction via interaction with the release factor 1 (eRF1) [45]. Human eRF1 has been shown to interact specifically with PP2Ac but not with the PR65/A or PR55/B subunits.

PP2Ac level can be regulated in vivo via a mechanism involving auto-inhibition during translation [62]. Presumably, PP2A dephosphorylates a specific phosphoprotein(s) from the translational apparatus leading to the inhibition of the enzyme synthesis. The autoinhibitory mechanism of PP2Ac synthesis explains the difficulties in obtaining overexpression of this protein [63]. It is therefore conceivable that the expression of PP2Ac is precisely regulated in order to ensure a constant amount of the PP2A protein, which may constitute an essential component of cellular signaling.

\section{Post-translation modifications of PP2Ac}

Another level of regulation of PP2A activity involves post-translational modifications of the C-terminal part of PP2Ac. The C-terminal part of PP2Ac is highly conserved among eukaryotes and may provide an important regulatory function.

Phosphorylation of tyrosine 307 by a variety of cellular and oncogenic tyrosine kinases inhibits PP2A activity.

Transient phosphorylation of Tyr 307 can be carried out by receptor and nonreceptor tyrosine kinases like Lyn, Fyn, Jak2, Src [64]. The most likely explanation for this observation is that at the beginning of signal processing many receptor and non-receptor kinases are activated, which results in massive phosphorylation of transducing proteins and therefore phosphatases should be temporally inactivated to let the signal pass from the receptors to cellular efectors. Moreover, PP2Ac is also phosphorylated by serine/theronine protein kinases [65]. The extensive phosphorylation of serine and threonine residues of PP2Ac, like the phosphorylation of Tyr 307, has an inhibitory effect on the enzyme activity. PP2A is capable of carrying out autodephosphorylation of phosphoserine and phosphotreonine [65].

Additionally, the C-terminal residue of the catalytic subunit, Leu 309, undergoes methylation. It has been shown that methylation is holoenzyme-specific and cell-cycle dependent [66]. Two enzymes are involved in this process, protein methyltransferase type IV and protein methylesterase (PME-1). Inactivation of the methyltransferase completely blocks $\mathrm{PP}_{\mathrm{T}}$ formation, which indicates that PP2Ac methylation is the trigger for dimer-trimer 
Table 1. Proteins that form complexes with PP2A

\begin{tabular}{|c|c|c|}
\hline Protein & Function & References \\
\hline \multicolumn{3}{|l|}{ Modulators of activity } \\
\hline $\mathrm{I}_{1}^{\mathrm{PP} 2 \mathrm{~A}}$ (PHAPI, mapmodulin) & Endogenous, heat-stable inhibitor of PP2A & 55 \\
\hline $\mathrm{I}_{2}^{\mathrm{PP} 2 \mathrm{~A}}(\mathrm{SET})$ & Endogenous, heat-stable inhibitor of PP2A & 56 \\
\hline HRX & $\begin{array}{l}\text { Binds PP2A via } \mathrm{I}_{2}{ }^{\mathrm{PP} 2 \mathrm{~A}} \text { (SET) inhibitor; } \\
\text { commonly mutated in acute leukemias }\end{array}$ & 57 \\
\hline FRAP/TOR/RAFT & Binds, phosphorylates and inactivates PP2A & 40,41 \\
\hline SV40 small-t & $\begin{array}{l}\text { Binds and inhibits the core dimer of PP2A; } \\
\text { displaces PR55/B subunits }\end{array}$ & 30 \\
\hline Adenovirus E4orf4 & $\begin{array}{l}\text { Binds to PP2A via PR55/B subunit; } \\
\text { causes downregulation of AP-1 }\end{array}$ & 32 \\
\hline HIV NCp7:Vpr & Binds to PR61/B'; activates PP2Ac subunit & 33 \\
\hline \multicolumn{3}{|l|}{ Modulators of specificity } \\
\hline Polyoma-virus small-t & Confers tyrosine phosphatase activity & 30 \\
\hline Polyoma-virus middle-t & Confers tyrosine phosphatase activity & 30 \\
\hline \multicolumn{3}{|l|}{ Assembly proteins } \\
\hline Tau & $\begin{array}{l}\text { PR55/B - Promotes PP2A binding to microtubules, } \\
\text { containing PP2A dephosphorylates Tau }\end{array}$ & 58 \\
\hline Neurofilament proteins & $\begin{array}{l}\text { Core dimer of PP2A dephosphorylates NF proteins, } \\
\text { promotes their assembly }\end{array}$ & 59 \\
\hline \multicolumn{3}{|l|}{ Scaffold proteins } \\
\hline CG-NAP & Binds regulatory RII subunit of PKA, PP2A and PP1 & 60 \\
\hline Axin & $\mathrm{PP} 2 \mathrm{~A} /$ axin/GSK-3/ $\beta$-catenin complex is formed & 61 \\
\hline
\end{tabular}

conversion [67]. Also it is the evidence for an interrelationship between PP2Ac carboxymethylation and PP2Ac holoenzyme assembly.

\section{CONCLUDING REMARKS}

Four families of variable subunits plus a number of associating proteins able to bind PP2A $_{D}$ have been identified, but only for some of those proteins a function in PP2A complexes was clearly shown. A possible strategy to uncover the function of the variable subunits is to methodically knock out the genes encoding them and assay the phenotypes of transgenic animals. The fundamental question in signal transduction of how the functions of protein kinases and protein phosphatases are coordinated is still partially an- swered. Work of many laboratories provided substantial evidence to support the hypothesis of " targeting subunits" of Cohen and Hubbard [68]. Most probably, in a living cell both protein kinases and protein phosphatases form high molecular complexes with scaffold proteins, which enable those enzymes to stay close enough to each other to have an effect on their counterpart. PP2A has been implicated in many different functions of a living cell, including cell cycle progression and oncogenic transformation. PP2A is essential for cell viability and therefore is tightly regulated on the translational level, by post-translation modifications, and by protein-protein interactions.

Our thanks go to Dr. Grażyna Dobrowolska for critical reading of the manuscript and $\mathrm{Ms}$ Katarzyna Róg for help in its preparation. 


\section{R E F E R E N C E S}

1. Krebs, E. (1986) The enzymology of control by phosphorylation. Enzymes 17, 3-20.

2. Mumby, M.C. \& Walter, G. (1993) Protein serine/threonine phosphatases: Structure, regulation and functions in cell growth. Physiol. Rev. 73, 673-692.

3. Oliver, C.J. \& Shenolikar, S. (1998) Physiological importance of protein phosphatase inhibitors. Frontiers Biosci. 3, 961-972.

4. Hunter, T. (1995) Protein kinases and phosphatases: The yin and yang of protein phosphorylation and signalling. Cell 80, 225-236.

5. Shenolikar, S. (1994) Protein serine/threonine phosphatases - new avenues for cell regulation. Annu. Rev. Cell Biol. 63, 55-86.

6. Barford, D. (1996) Molecular mechanisms of the protein serine/threonine phosphatases. Trends Biochem. Sci. 21, 407-412.

7. Wera, S. \& Hemmings, B.A. (1995) Serine/ threonine phosphatases. Biochem. J. 311, $17-29$.

8. Millward, T.A., Zolnierowicz, S. \& Hemmings, B.A. (1999) Regulation of protein kinase cascades by protein phosphatase 2A. Trends Biochem. Sci. 24, 186-191.

9. Cohen, P.T. (1997) Novel protein serine/threonine phosphatases: Variety is the spice of life. Trends Biochem. Sci. 22, 245-251.

10. Zolnierowicz, S. (2000) Type 2A protein phosphatase, the complex regulator of numerous signalling pathways. Biochem. Pharmacol. 60, 1225-1235.

11. Andjelkovic, N., Zolnierowicz, S., MayerJaekel, R.E. \& Hemmings, B.A. (1996) Structure, regulation and targeting of protein phosphatase 2A; in: NATO ASI Series; vol. $\mathrm{H} 102$, Interacting protein domains, their role in signal and energy transduction (Heilmeyer, L., ed.) pp. 196-205, Springer-Verlag Berlin, Heidelberg.
12. Mayer-Jaekiel, R.E. \& Hemmings, B.A. (1994) Protein phosphatase type 2A-menage a trois. Trends Cell Biol. 4, 287-291.

13. Mayer, R.E., Khew-Goodall, Y., Stone, S.R. \& Hemmings, B.A.(1991) Structure and expression of protein phosphatase PP2A. Adv. Prot. Phosphatases 6, 125-143.

14. Groves, M.R., Hanlon, N., Turowski, P., Hemmings, B.A. \& Barford, D. (1999) The structure of the protein phosphatase $2 \mathrm{~A}$ PR65/A subunit reveals the conformation of its 15 tandemly repeated HEAT motifs. Cell 96, 99-110.

15. Moreno, C.S., Park, S., Nelson, K., Ashby, D., Hubalek, F., Lane, W.S. \& Pallas, D.C. (2000) WD40 repeat proteins striatin and S/G(2) nuclear autoantigen are members of a novel family of calmodulin-binding proteins that associate with protein phosphatase 2A. J. Biol. Chem. 275, 5257-5263.

16. Żołnierowicz, S., Van Hoof, C., Andjelkovic, N., Cron, P., Stevens, J., Merlevede, W., Goris, J. \& Hemmings, B.A. (1996) The variable subunit associated with protein phosphatases $2 \mathrm{~A}_{0}$ defines a novel multimember family of regulatory subunits. Biochem. J. 317, 187-194.

17. Healy, A.M., Zolnierowicz, S., Stapleton, A.E., Goebl, M., DePaoli-Roach, A.A. \& Pringle, J.R. (1991) CDC55, a Saccharomyces cerevisiae gene involved in cellular morphogenesis: Identification, characterization and homology to the $\mathrm{B}$ subunit of mammalian type $2 \mathrm{~A}$ protein phosphatase. Mol. Cell. Biol. 11, 5767-5780.

18. Mayer-Jaekel, R.E., Ohkura, H., Gomes, R., Sunkel, C.E., Baumgartner, S., Hemmings, B.A. \& Glover, D.M. (1993) The 55 kd regulatory subunit of Drosophila protein phosphatase $2 \mathrm{~A}$ is required for anaphase. Cell $\mathbf{7 2}$, 621-633.

19. Turowski, P., Myles, T., Hemmings, B.A., Fernandez, A. \& Lamb, N.J. (1999) Vimentin dephosphorylation by protein phosphatase $2 \mathrm{~A}$ 
is modulated by the targeting subunit B55. Mol. Biol. Cell 10, 1997-2015.

20. Mayer, R.E., Hendrix, P., Cron, P., Matthies, R., Stone, S.R., Goris, J., Merlevede, W., Hofsteenge, J. \& Hemmings, B.A. (1991) Structure of the $55-\mathrm{kDa}$ regulatory subunit of protein phosphatase 2A: Evidence for a neuronal-specific isoform. Biochemistry 30, 35893597.

21. McCright, B., Rivers, A.M., Audlin, S. \& Virshup, D.M. (1996) The B56 family of protein phosphatase 2A (PP2A) regulatory subunits encodes differentiation-induced phosphoproteins that target PP2A to both nucleus and cytoplasm. J. Biol. Chem. 271, 22081-22089.

22. Graeber, T.G., Peterson, J.F., Tsai, M., Monica, K., Fornace, A., J., Jr. \& Giaccia, A., J. (1994) Hypoxia induces accumulation of p53 protein, but activation of a G1-phase checkpoint by low-oxygen conditions is independent of p53 status. Mol. Cell. Biol. 14, 6264-6277.

23. Okamoto, K., Kamibayashi, C., Serrano, M., Prives, C., Mumby, M.C. \& Beach, D. (1996) p53-dependent association between cyclin $\mathrm{G}$ and the $\mathrm{B}^{\prime}$ subunit of protein phosphatase $2 \mathrm{~A}$. Mol. Cell. Biol. 16, 6593-6602.

24.Li, X., Yost, H.J., Virshup, D.M. \& Seeling, J.M. (2001) Protein phosphatase 2A and its B56 regulatory subunit inhibit Wnt signaling in Xenopus. EMBO J. 20, 4122-4131.

25. Seeling, J.M., Miller, J.R, Gil, R., Moon, R.T., White, R. \& Virshup, D.M. (1999) Regulation of beta-catenin signaling by the B56 subunit of protein phosphatase 2A. Science 283, 20892091.

26. Cegielska, A., Shaffer, S., Derua, R., Goris, J. \& Virshup, D.M. (1994) Different oligomeric forms of protein phosphatase type 2A activate and inhibit simian virus 40 DNA replication. Mol. Cell. Biol. 14, 4616-4623.
27. Yan, Z., Fedorov, S.A., Mumby, M.C. \& Williams, R.S. (2000) PR48, a novel regulatory subunit of protein phosphatase $2 \mathrm{~A}$, interacts with Cdc6 and modulates DNA replication in human cells. Mol. Cell. Biol. 20, 1021-1029.

28. Voorhoeve, P.M., Watson, R.J., Farlie, P.G, Bernards, R. \& Lam, E.W. (1999) Rapid dephosphorylation of $\mathrm{p} 107$ following UV radiation. Oncogene 18, 679-688.

29. Kamibayashi, C. \& Mumby, M.C. (1995) Control of protein phosphatase $2 \mathrm{~A}$ by multiple families of regulatory subunits. Adv. Prot. Phosphatases 9, 199-214.

30.Pallas, D.C., Shahrik, L.K., Martin, B.L., Jaspers, S., Miller, T.B., Brautigan, D.L. \& Roberts, T.M. (1990) Polyoma small and middle $\mathrm{T}$ antigens and SV40 small $\mathrm{t}$ antigen form stable complexes with protein phosphatase 2A. Cell 60, 167-176.

31. Walter, G. \& Mumby, M.C. (1993) Protein serine/threonine phosphatases and cell transformation. Biochim. Biophys. Acta 1155, $207-$ 226.

32. Kleinberger, T. \& Shenk, T. (1993) Adenovirus E4orf4 protein binds to protein phosphatase $2 \mathrm{~A}$ and the complex down regulates E1A-enhanced junB transcription. J. Virol. 67, 75567560 .

33.Tung, H.Y., De Rocquigny, H., Zhao, L.J., Cayla, X., Roques, B.P. \& Ozon, R. (1997) Direct activation of protein phosphatase-2A0 by HIV-1 encoded protein complex NCp7:vpr. FEBS Lett. 401, 197-201.

34. Cowley, S., Paterson, H., Kemp, P. \& Marshall, C.J. (1994) Activation of MAP kinase kinase is necessary and sufficient for PC12 differentiation and for transformation of $\mathrm{NIH}$ 3T3 cells. Cell 77, 841-852.

35. Gomez, N. \& Cohen, P. (1991) Dissection of the protein kinase cascade by which nerve growth factor activates MAP kinases. Nature 353, $170-173$. 
36. Sontag, E. (2001) Protein phosphatase 2A: The Trojan Horse of cellular signaling. Cell Signal 13, 7-16.

37. Sontag, E., Fedorov, S., Kamibayashi, C., Robbins, D., Cobb, M. \& Mumby, M.C. (1993) The interaction of SV40 small tumor antigen with protein phosphatase $2 \mathrm{~A}$ stimulates the MAP kinase pathway and induces cell proliferation. Cell 75, 887-897.

38. Santoro, M.F., Annard, R.R., Robertson, M.M., Peng, Y.W., Brady, M.J., Mankovich, J.A., Hacket, M.C., Ghayur, T., Walter, G., Wong, G.G. \& Giegel, D.A. (1998) Regulation of protein phosphatase $2 \mathrm{~A}$ activity by caspase-3 during apoptosis. J. Biol. Chem. 273, 13119-13128.

39. Orth, K., O`Rourke, K., Salvesen, G.S. \& Dixit, V.M. (1996) Molecular ordering of apoptotic mammalian CED-3/ICE-like proteases. J. Biol. Chem. 271, 20977-20980.

40. Chen, J., Peterson, R.T. \& Schreiber, S.L. (1998) Alpha 4 associates with protein phosphatases 2A, 4 and 6. Biochem. Biophys. Res. Commun. 247, 827-832.

41. Murata, K., Wu, J. \& Brautigan, D.L. (1997) B cell receptor-associated protein alpha4 displays rapamycin-sensitive binding directly to the catalytic subunit of protein phosphatase 2A. Proc. Natl. Acad. Sci. U.S.A. 94, 106241069.

42. Kawabe, T., Muslin, A.J. \& Korsmeyer, S.J. (1997) HOX11 interacts with protein phosphatases PP2A and PP1 and disrupts a G2/M cell-cycle checkpoint. Nature 385, 454-458.

43. Inoue, R., Usui, H., Tanabe, O., Nishito, Y., Shimizu, M. \& Takeda, M. (1999) Studies on functions of the $63-\mathrm{kDa} \mathrm{A}-$ and $74-\mathrm{kDa}$ $\mathrm{B}^{\prime}$ (delta)-regulatory subunits in human erythrocyte protein phosphatase 2A: Dissociation and reassociation of the subunits. J. Biochem. 126, $1127-1135$.

44. Hong, Y. \& Sarge, K.D. (1999) Regulation of protein phosphatase $2 \mathrm{~A}$ activity by heat shock transcription factor 2. J. Biol. Chem. 274, 12967-12970.

45. Andjelkovic, N., Zolnierowicz, S., Van Hoof, C., Goris, J. \& Hemmings, B.A. (1996) The catalytic subunit of protein phosphatase $2 \mathrm{~A}$ associates with the translation termination factor eRF1. EMBO. J. 15, 7156-7167.

46. Lechward, K., Zolnierowicz, S. \& Hemmings, B.A. (1999) Eukaryotic translation termination factor 1 associates with protein phosphatase $2 \mathrm{~A}$ and targets it to ribosomes. Biochemistry (Moscow) 64, 1378-1386.

47. Maniatis, T. (1999) A ubiquitin ligase complex essential for the NF-kappaB, Wnt/Wingless and Hedgehog signaling pathways. Genes Dev. 13, 505-510.

48. Gotz, J., Probst, A., Mistl, C., Nitsch, R.M. \& Ehler, E. (2000). Distinct role of protein phosphatase $2 \mathrm{~A}$ subunit $\mathrm{C}$ alpha in the regulation of E-cadherin and beta-catenin during development. Mech. Dev. 93, 83-93.

49. MacKintosh, C. \& MacKintosh, R.W. (1994) Inhibitors of protein kinases and phosphatases. Trends Biochem. Sci. 19, 444-448.

50.Evans, D.R. \& Simon, J.A. (2001) The predicted beta12-beta13 loop is important for inhibition of PP2Ac alpha by the antitumor drug fostriecin. FEBS Lett. 498, 110-115.

51. Calin, G.A., di Iasio, M.G., Caprini, E., Vorechovsky, I., Natali, P.G., Sozzi, G., Croce, C.M., Barbanti-Brodano, G., Russo, G. \& Negrini, M. (2000) Low frequency of alterations of the alpha (PPP2R1A) and beta (PPP2R1B) isoforms of the subunit A of the serine-threonine phosphatase $2 \mathrm{~A}$ in human neoplasms. Oncogene 19, 1191-1195.

52.Wang, S.S., Esplin, E.D., Li, J.L., Huang, L., Gazdar, A., Minna, J. \& Evans, G.A. (1998) Alterations of the PPP2R1B gene in human lung and colon cancer. Science 282, 284-287. 
53. Nigg, E.A. (2001) Mitotic kinases as regulators of cell division and its checkpoints. Nat. Rev. Mol. Cell Biol. 2, 21-32.

54. Karaisoku, A., Jessus, C., Brassac, T. \& Ozon, R. (1999) Phosphatase $2 \mathrm{~A}$ and polo kinase, two antagonistic regulators of cdc25 activation and MPF auto-amplification. J. Cell Sci. 112, 3747-3756.

55. Li, M., Makkinje, A. \& Damuni, Z. (1996) Molecular identification of I1PP2A, a novel potent heat-stable inhibitor protein of protein phosphatase 2A. Biochemistry 35, 6987-6998.

56. Li, M., Makkinje, A. \& Damuni, Z. (1996) The myeloid leukaemia associated protein SET is a potent inhibitor of protein phosphatase 2A. $J$. Biol. Chem. 271, 11059-11062.

57. Adler, H.T., Nallaseth, F.S., Walter, G. \& Tkachuk, D.C. (1997) HRX leukemic fusion proteins form a heterocomplex with the leukemia-associated protein SET and protein phosphatase 2A. J. Biol. Chem. 272, 28407-28414.

58.Sontag, E., Nunbhakdi-Craig, V., Lee, G., Brandt, R., Kamibayashi, C., Kuret, J., White, C.L., 3rd, Mumby, M.C. \& Bloom, G.S. (1999) Molecular interactions among protein phosphatase 2A, tau and microtubules. Implications for the regulation of tau phosphorylation and the development of tauopathies. J. Biol. Chem. 274, 25490-25498.

59. Saito, T., Shima, H., Osawa, Y., Nagao, M., Hemmings, B.A., Kishimoto, T. \& Hisanaga, S. (1995) Neurofilament-associated protein phosphatase 2A: Its possible role in preserving neurofilaments in filamentous states. Biochemistry 34, 7376-7384.

60. Takahashi, M., Shibata, H., Shimakawa, M., Miyamoto, M., Mukai, H. \& Ono, Y. (1999) Characterization of a novel giant scaffolding protein, CG-NAP, that anchors multiple sig- naling enzymes to centrosome and the Golgi apparatus. J. Biol. Chem. 274, 17267-17274.

61. Hsu, W., Zeng, L. \& Costantini, F. (1999) Identification of a domain of axin that binds to the serine/threonine protein phosphatase $2 \mathrm{~A}$ and a self-binding domain. J. Biol. Chem. 274, $3439-3445$.

62. Baharians, Z. \& Schontal, A.H. (1998) Autoregulation of protein phosphatase type $2 \mathrm{~A}$ expression. J. Biol. Chem. 273, 19019-19024.

63. Swiatek, W., Sugajska, E., Lankiewicz, L. \& Zolnierowicz, S. (2000) Biochemical characterization of recombinant subunits of type $2 \mathrm{~A}$ protein phosphatase overexpressed in Pichia pastoris. Eur. J. Biochem. 267, 5209-5216.

64. Chen, J., Parsons, S. \& Brautigan, D.L. (1994) Tyrosine phosphorylation of protein phosphatase $2 \mathrm{~A}$ in response to growth stimulation and v-src transformation of fibroblasts. J. Biol. Chem. 269, 7957-7962.

65. Damuni, Z., Xiong, H. \& Li, M. (1994) Autophosphorylation-activated protein kinase inactivates the protein tyrosine phosphatase activity of protein phosphatase 2A. FEBS Lett. 352, 311-314.

66. Favre, B., Zolnierowicz, S., Turowski, P. \& Hemmings, B.A., (1994) The catalytic subunit of protein phosphatase $2 \mathrm{~A}$ is carboxyl-methylated in vivo. J. Biol. Chem. 269, 1631116316.

67. Wu, J., Tolstykh, T., Lee, J., Boyd, K., Stock, J.B. \& Broach, J.R., (2000) Carboxyl methylation of the phosphoprotein phosphatase $2 \mathrm{~A}$ catalytic subunit promotes its functional association with regulatory subunits in vivo. EMBO J. 19, 5672-5681.

68. Hubbard, M.J. \& Cohen, P. (1993) On target with a new mechanism for the regulation of protein phosphorylation. Trends Biochem. Sci. 18, 172-177. 